\title{
EFFECTS OF CLINICAL MASTITIS ON REPRODUCTIVE PERFORMANCE IN COWS IN VEDIO STATION - SYRIA
}

\author{
V.M. NEZAR SOLAIMAN* and A.A EL-MONLA** \\ *MSC. Vet. Med. (D.V.M) in Veterinary Science, Buplic Health and preventive Medicine-Faculty of Veterinary Medicine, Hamaa University. \\ ** Professor of Vet. Hgg. and Zoonoses, Faculty of Veterinary Medicine, Hamaa University. \\ Email: nezar1242011@ hotmail.com
}

\section{ABSTRACT}

Received at: $20 / 12 / 2014$

Accepted: 15/2/2015
The purpose of this study was to determine the influence of clinical mastitis on reproductive performance in first lactation holishtein cows in Vedio farm in Syria. Cows were divided as follows: group 1, clinical mastitis before first artificial insemination $(n=34)$; group 2, clinical mastitis between first artificial insemination and pregnancy $(n=19)$; group 3, clinical mastitis after confirmed pregnancy $(n=13)$; and group 4, control cows $(n=23)$ with no clinical mastitis. The number of days to first AI was significantly greater for cows with clinical mastitis before first AI $(99.3 \mathrm{~d})$ than for all other groups Gr2 (77.8 d), Gr3(75.7 d) and Control(76.5 d). Artificial inseminations per conception were significantly greater for cows with clinical mastitis after first Artificial inseminations Gr2(3.68) than for cows with clinical mastitis before first Artificial inseminations Gr1 (2.3), cows with clinical mastitis after confirmed pregnancy Gr3(2.07) or cows with no clinical mastitis Control (2.04). The number of days to conception for cows with clinical mastitis after first AI Gr2 (151.7 d) was significantly greater than that for control cows $(95.6 \mathrm{~d})$, for cows with clinical mastitis before first Artificial inseminations $\operatorname{Gr} 1(118.1 \mathrm{~d})$ and that for cows that developed clinical mastitis after confirmed pregnancy $(98.5 \mathrm{~d})$. Clinical mastitis during early lactation markedly influenced reproductive performance of holishtein cows in Vedio farm in Syria.

Key words: Vedio, cow, mastitis, reproductive performance

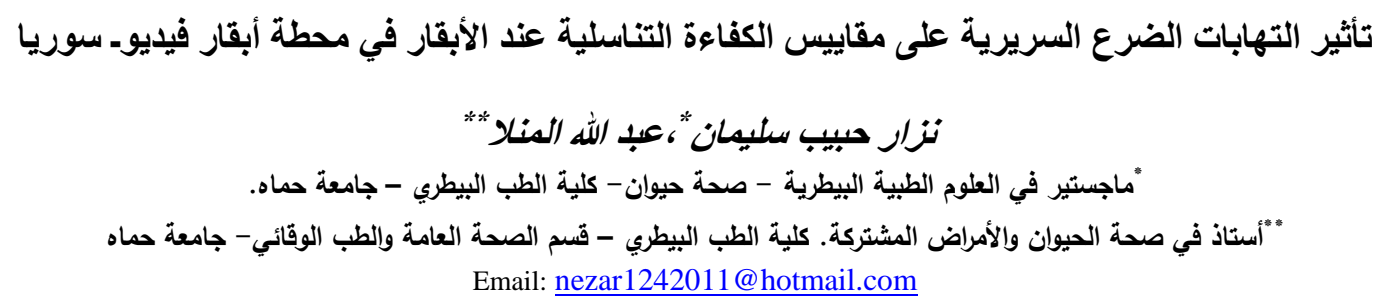

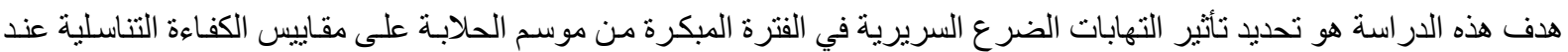

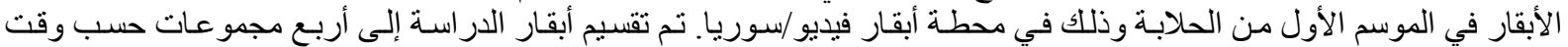

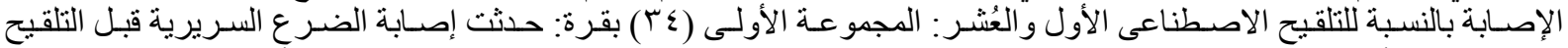

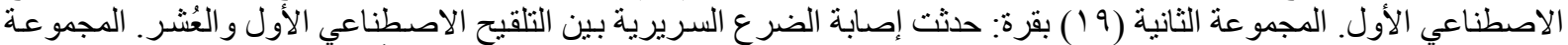

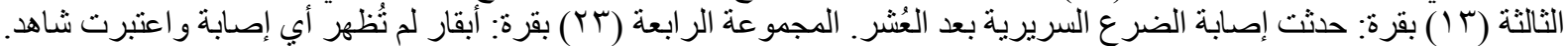

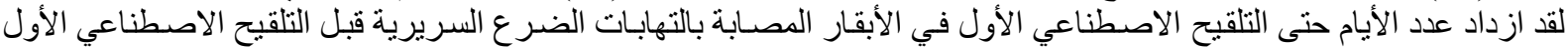

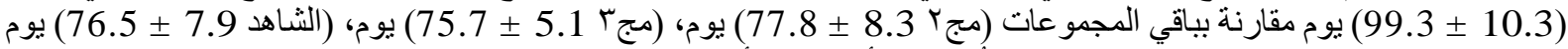

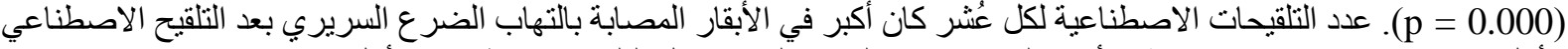

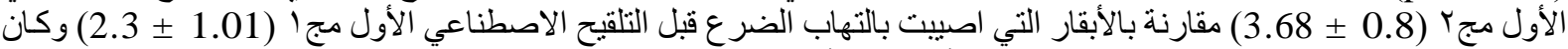

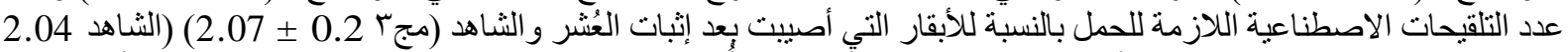

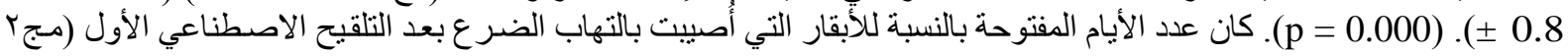




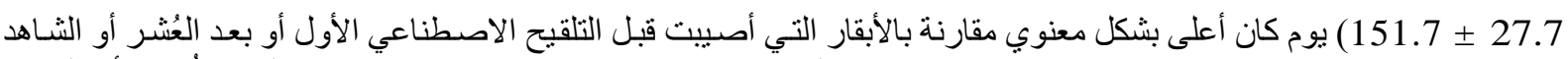

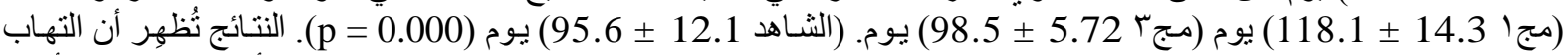
الضرع السريري خلال الفترة المبكرة من موسم الحلابة يؤثر بشكل واضح على على مقاييس الكفاءة التناسلية عند الأبقار في محطة أبقار

\section{INTRODUCTION}

المقدمـة

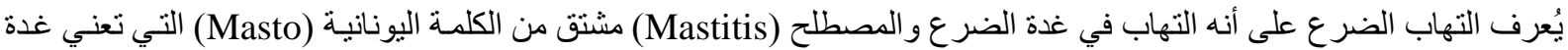

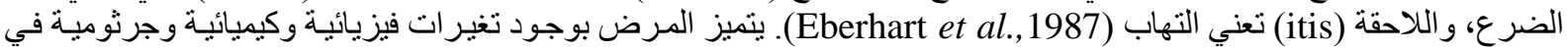

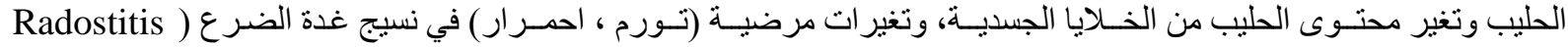

. (et al., 1994

العلامات السريرية الملاحظة في التهاب الضر ع السريري هي وجود جلطات في الحليب وتغير مظهر الحليب و انخفاض الإنتاج بشكل

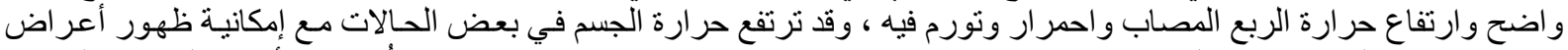

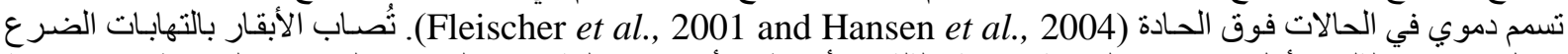

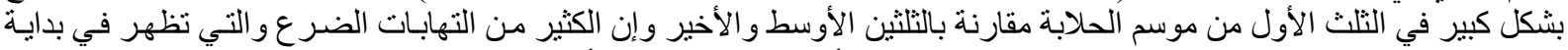

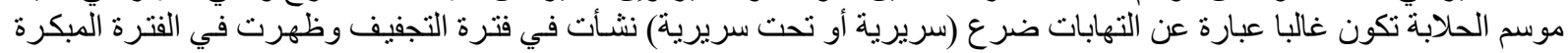
من موسم الحلابة (Smith et al.,1985).

تُعد الجر اثثم الإيجابية و السلبية الغرام من أهم مسبيات التهابـات الضـرع، بالإضـافة لذلك يمكن للفيروسات و الفطور أن تُحدث أيضـا

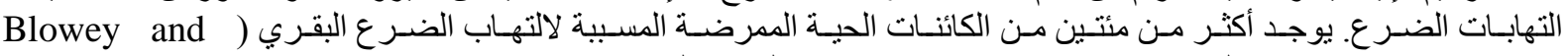

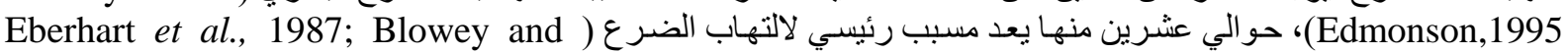
.(Edmondson, 1995

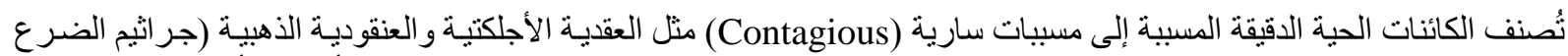

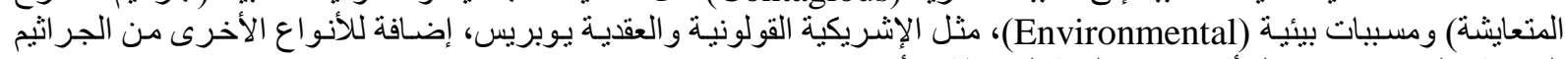
المعوية والتي تتو اجد بثكل أساسي في البيئة المحيطة بالأبقار.

Staphylococcus aureus, Streptococcus agalactiae, Streptococcus (الكائنات الأكثر شيو عا في التهابات الضر ع هي (H) .(Harmon, 1994) (dysgalactiae, Streptococcus uberis, Arcanobacterium pyogenes and coliforms

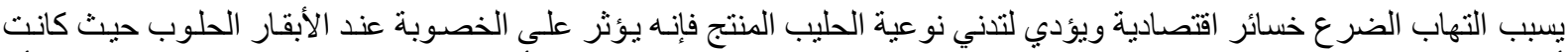

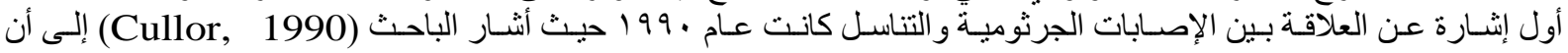

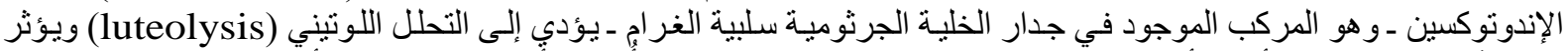

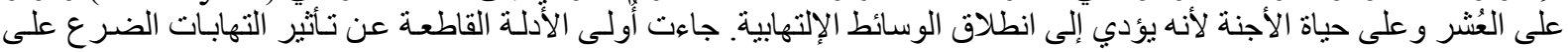

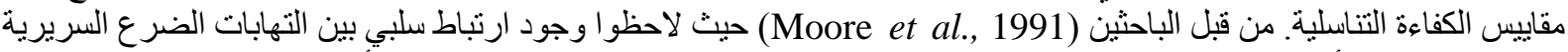

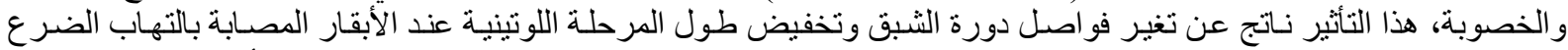

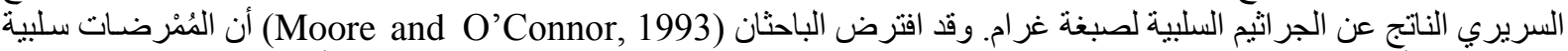

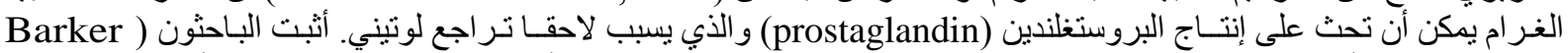

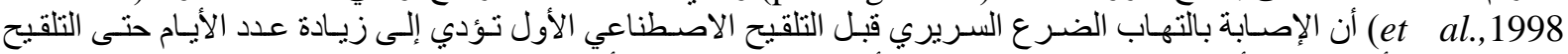

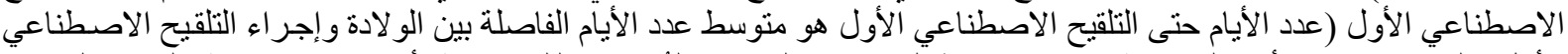

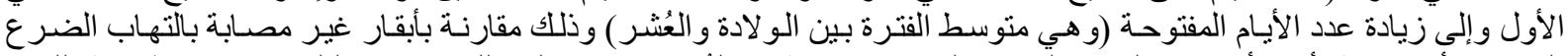

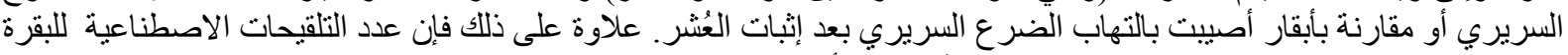

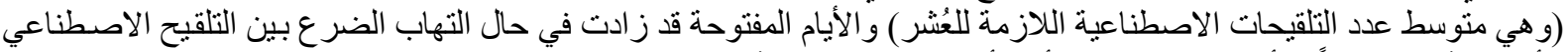

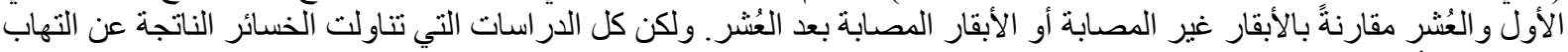

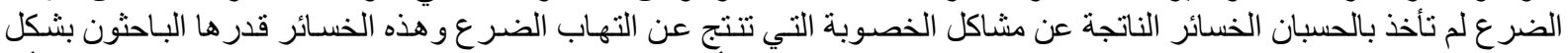

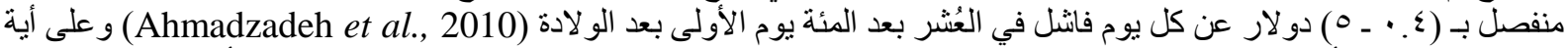

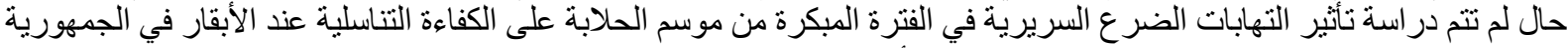

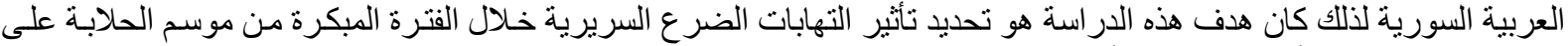
الكفاءة التناسلية عند الأبقار في محطة أبقار فيديو في الجمهورية العربية السورية. 


\section{MATERIALS and METHODS \\ مواد وطر ائق العمل}

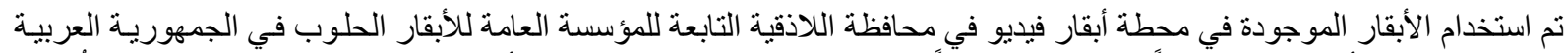

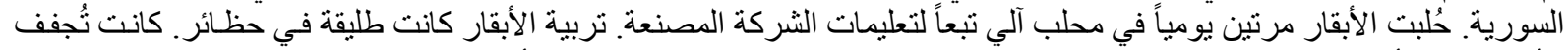

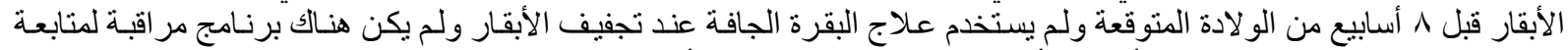

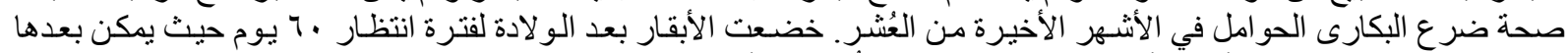

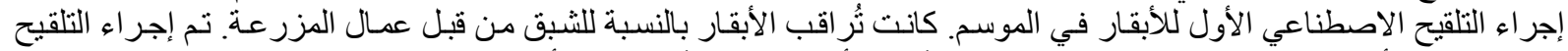
الإصطناعى للأبقار الثُبقة من قبل الطبيب البيطري. ويُجرى أيضا كثف العُشر لكل الأبقار بعد التلقيح الاصنطناعي بـ ـ0 ـ 10 يوم.

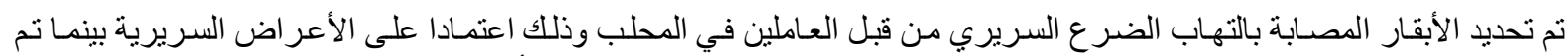

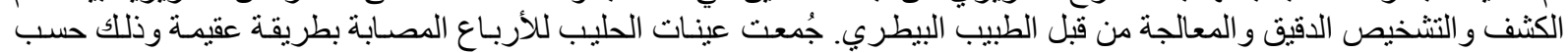

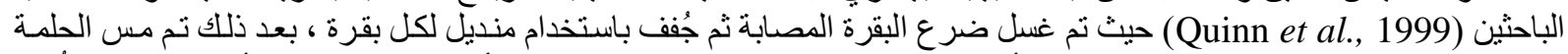

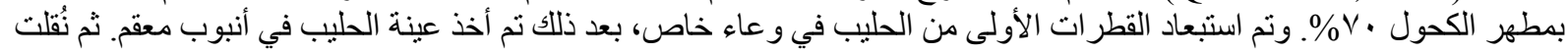
العينات في الحافظات التي تحتوي على قو الب التلج خلال نقلها إلى مختبر ات كلية الطب البع البطري في مدينة حماه.

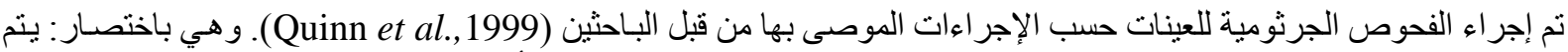

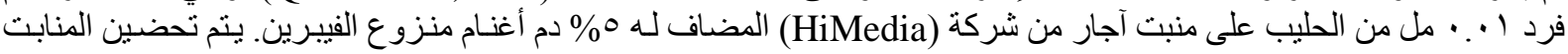

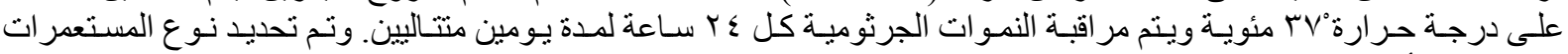

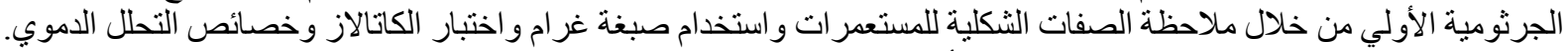

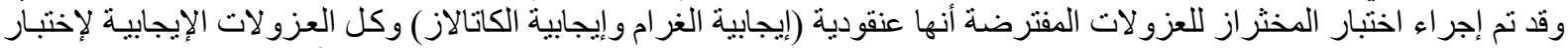

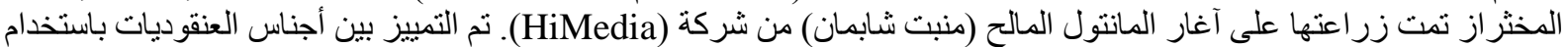

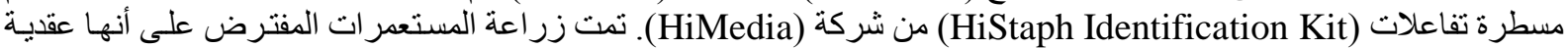

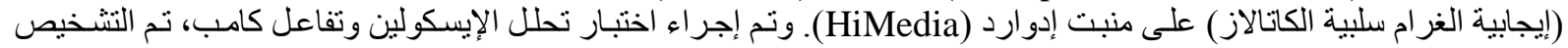

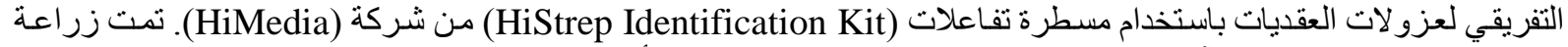
HiAssorted العزو لات سلبية الغر ام على آغار ماكونكي (HiMedia) وتم التفريق بين أنو اعها باستخدام مسطرة تفاعلات

(Biochemical Kit من شركة (HiMedia)

$$
\begin{aligned}
& \text { تمت قر اءة نتائج الزرع الجرثومي كمايلي: }
\end{aligned}
$$

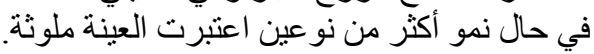

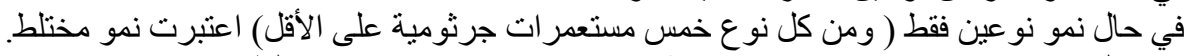

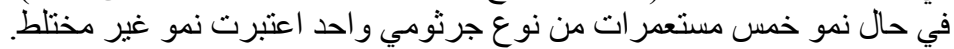

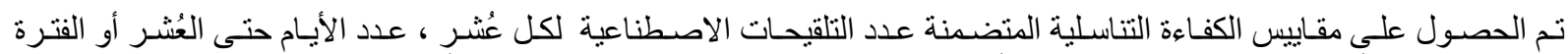

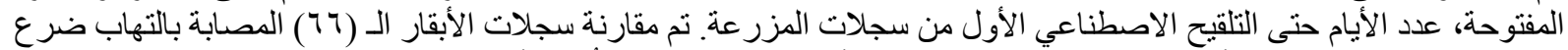

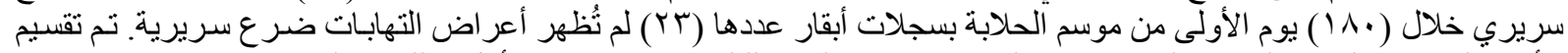

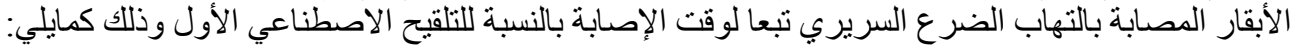

المجمو عة الأولى (ع ب) بقرة: حدثت إصابة الضرع السريرية قبل التلقيح الاصطناعي الأول.

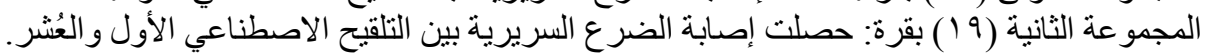

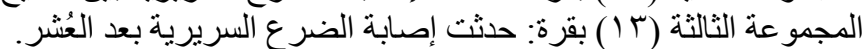

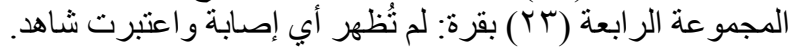

تمت دراسة الفروق بين المجموعات بطريقة تحليل الفرق الوحيد (ANOVA) باستخدام برنامج (SPSS) وحسب الباحث (-Julie)

.(Pallant, 2005

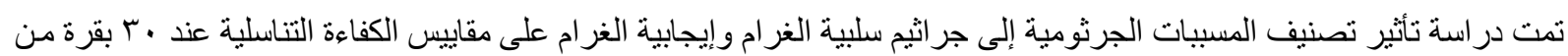

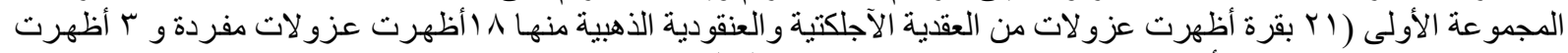
عزو لات مزدوجة ، ب ا ا بقرة أظهرت عزو لألات مفردة من الإشريكية القولونية).

\section{RESULTS}

$$
\text { النتأتسـج }
$$

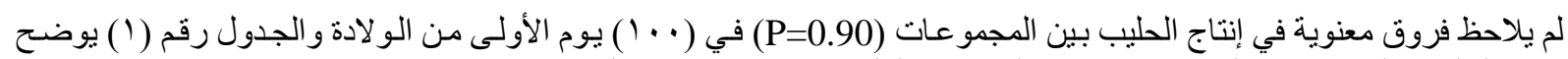

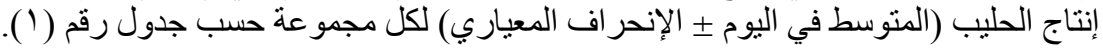

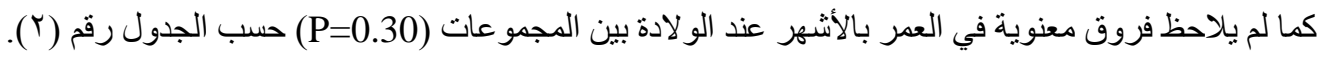




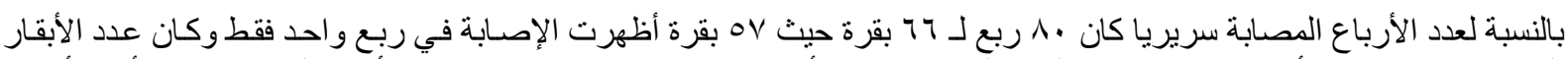

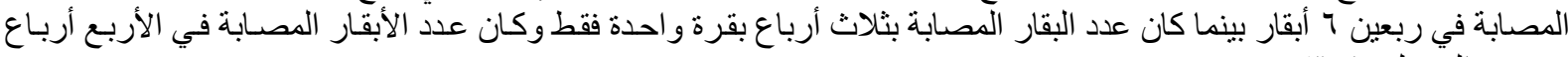
بقرتين (الجدول رقم ؟ ب).

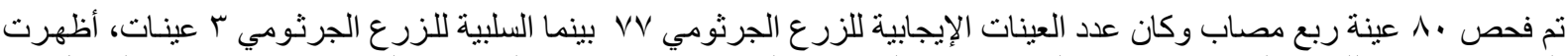

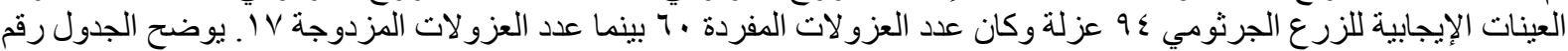

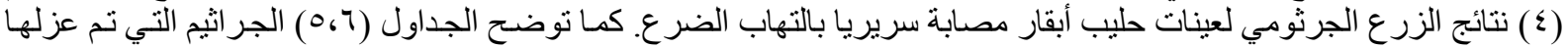

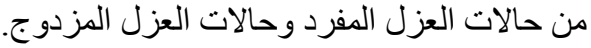

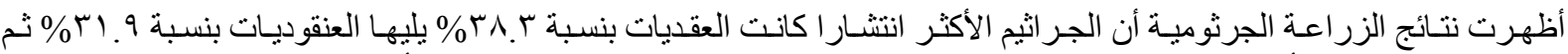

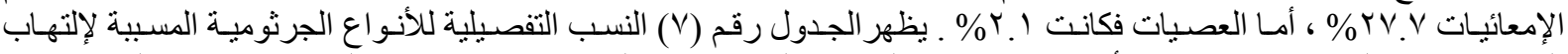

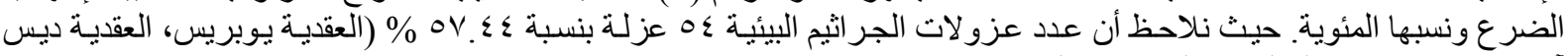

آجالاكتيا، الإشريكية القولونية، المكورات المعوية).

أظهر تحليل الفروق عدم وجود تأثير معنوي لصنف الجر اثيم إن كانت سلبية الغرام أو إيجابية الغرام على الفترة المفتوحة (P=0.61)

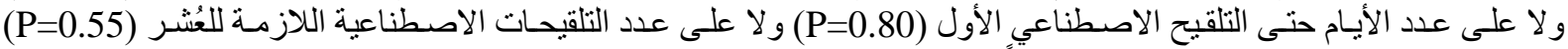

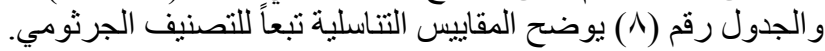

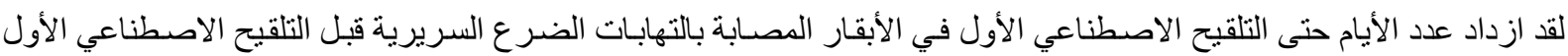

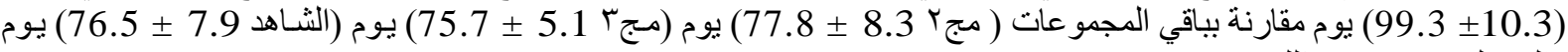
والجدول (9) يوضح ذلك.

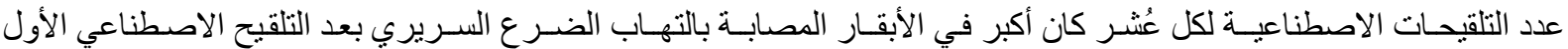

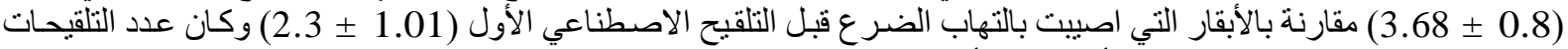

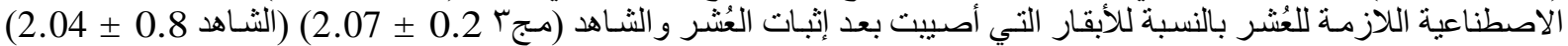
والجدول (· (1) يوضح ذللك.

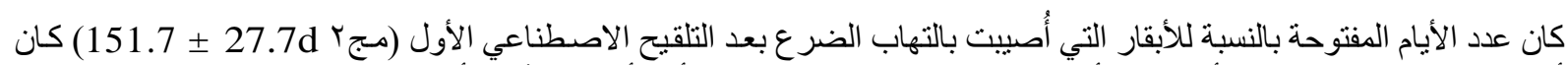

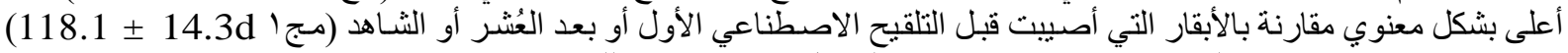

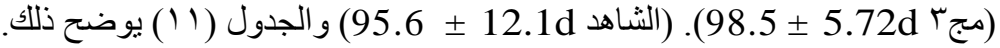

جدول ا : منوسط إنتاج الحليب للمجموعات في ( · ( ) يوم الأولى من الو لادة.

\begin{tabular}{|c|c|}
\hline إنتاج الحليب/ كغ/ & المجمو عة \\
\hline $2.9 \pm 19.62$ & المجمو عة الأولى \\
\hline $3.05 \pm 19.87$ & المجمو عة الثانية \\
\hline $3.01 \pm 19.66$ & المجمو عة الثالثة \\
\hline $2.28 \pm 19.77$ & الثناهد \\
\hline
\end{tabular}

جدول ץ : منوسط العمر بالأشهر عند الو لادة لمجموعات الدراسة. 3.05

\begin{tabular}{|c|c|}
\hline الإنتاج كغ & المجمو عة \\
\hline $1.6 \pm 27.5$ & المجمو عة الأولى \\
\hline $1.6 \pm 27.42$ & الدجموعة الثانية \\
\hline $1.26 \pm 27.61$ & المجمو عة الثالثة \\
\hline $1.23 \pm 26.8$ & الثـاهد \\
\hline
\end{tabular}


Assiut Vet. Med. J. Vol. 61 No. 144 January 2015

جدول ب: توزع الأبقار حسب الإصابة في ربع أو أكثر.

\begin{tabular}{|c|c|c|c|c|c|c|}
\hline في أربعة أرباع الأبقابة & المصابة في ثلاثة & المصابة في ربعين & في ربع الأبقار المصابة & عدد الأرباع & عدد الأبقار & المجمو عة \\
\hline 1 & 1 & 3 & 29 & 42 & 34 & لمجمو عة الأولى \\
\hline 1 & 0 & 0 & 18 & 22 & 19 & المجمو عة الثانية \\
\hline 0 & 0 & 3 & 10 & 16 & 13 & المجمو عة الثالثة \\
\hline 2 & 1 & 6 & 57 & 80 & 66 & مجموع \\
\hline
\end{tabular}

\begin{tabular}{|c|c|}
\hline 80 & عدد عينات الأرباع الدفحوصة \\
\hline 3 & عدد عينات الأرباع السلبية للزرع الجرثومي \\
\hline 77 & عدد عينات الأرباع الإيجابية للزرع الجرثومي \\
\hline 60 & عدد العينات التي أظهرت عزو لات الدفردة \\
\hline 17 & عدد العينات التي أظهرت عزو لات مزدوجة \\
\hline 94 & مجموع عدد العزو لات \\
\hline
\end{tabular}

$$
\text { جدول ه: العزل الجرثومي المزدوج }
$$

\begin{tabular}{|c|c|}
\hline 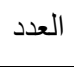 & العزل الجرثومي المزدوج \\
\hline 3 & عنقودية ذهبية + عقدية آجلكتية \\
\hline 4 & عنقودية ذهبية + أشريكية قولونية \\
\hline 4 & عقدية يوبريس + عقدية ديس آجالاكتيا \\
\hline \multirow[t]{2}{*}{6} & عنقودية سلبية التخثر + أثريكية قولونية \\
\hline & جدول \': العزل الجرثومي المفرد. \\
\hline 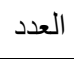 & العزل الجرثومي المفرد \\
\hline 14 & العنقودية الذهبية \\
\hline 3 & العنقودية سلبية التخثر \\
\hline 5 & العقدية الآجلكتة \\
\hline 9 & العقدية ديس آجالكتيا \\
\hline 11 & العقدية يوبريس \\
\hline 11 & إيشريكية قولونية \\
\hline 5 & المكور ات المعوية \\
\hline 2 & جنس العصيات \\
\hline 60 & 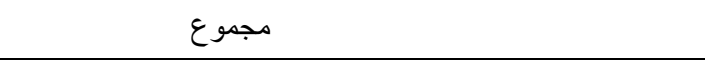 \\
\hline
\end{tabular}


Assiut Vet. Med. J. Vol. 61 No. 144 January 2015

جدول V: التوزيع التفصيلي للجر اثيم المسببة لإلتهابات الضر ع ونسبها المئوية عند أبقار الدراسة.

\begin{tabular}{|c|c|c|c|c|c|c|c|c|c|}
\hline \multirow[t]{2}{*}{$\%$} & \multirow{2}{*}{ العزولات } & \multicolumn{3}{|c|}{ العزو لات حسب } & \multirow[t]{2}{*}{ \% العزولات } & \multirow[t]{2}{*}{ العزولات } & \multirow[t]{2}{*}{ Pathogen } & \multirow[t]{2}{*}{ الجرثوم } & \multirow[t]{2}{*}{ الجرثمية } \\
\hline & & 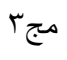 & مجr & مجا & & & & & \\
\hline \multirow[t]{2}{*}{0.319} & \multirow[t]{2}{*}{30} & 5 & 5 & 11 & 0.223 & 21 & $\begin{array}{l}\text { Staphylococcus } \\
\text { aureus }\end{array}$ & العنقودية الذهبية & \multirow[t]{2}{*}{ العنقوديات } \\
\hline & & 1 & 3 & 5 & 0.096 & 9 & $\begin{array}{l}\text { Coagulase-negativ } \\
\text { staphylococci }\end{array}$ & العنقودية سلبية & \\
\hline \multirow[t]{3}{*}{0.378} & \multirow[t]{3}{*}{36} & 2 & 2 & 4 & 0.085 & 8 & $\begin{array}{l}\text { Streptococcus } \\
\text { agalactiae }\end{array}$ & العقدية الآجلكتة & \multirow[t]{3}{*}{ العقديات } \\
\hline & & 3 & 4 & 6 & 0.138 & 13 & $\begin{array}{c}\text { Streptococcus } \\
\text { dysgalactiae }\end{array}$ & الجقالكتية ديس & \\
\hline & & 2 & 4 & 9 & 0.16 & 15 & $\begin{array}{c}\text { Streptococcus } \\
\text { uberis }\end{array}$ & العقدية يو بريس & \\
\hline \multirow[t]{2}{*}{0.276} & \multirow[t]{2}{*}{26} & 1 & 4 & 16 & 0.223 & 21 & coli Escherichia & إيشريكية قولونية & \multirow[t]{2}{*}{ الإمعائيات } \\
\hline & & 1 & 2 & 2 & 0.053 & 5 & $\begin{array}{l}\text { Enterococcus } \\
\quad \text { faecalis }\end{array}$ & المكورات المعية & \\
\hline 0.021 & 2 & 2 & 0 & 0 & 0.021 & 2 & species Bacillus & جنس العصيات & العصيات \\
\hline 0.994 & 94 & 17 & 24 & 53 & 1 & 94 & ل الات & مجموع العز & \\
\hline \multicolumn{10}{|c|}{ تم حساب النسبة المئوية للعزو لات كنسبة مئوية من عدد العزو لات الإيجابية ؟9 عزلة } \\
\hline \multicolumn{10}{|c|}{ جدول ^: يظهر المتوسط الحسابي للمقاييس التناسلية تبعا لتصنيف الجر اثيم حسب صبغة غرام. } \\
\hline ل ل للازمة & تل الاصطناعل & التلقيح & & & 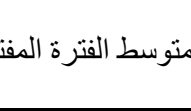 & & متوسط عدد الأيام حتى التلقيح & \multirow{2}{*}{\multicolumn{2}{|c|}{ تصنيف الجر اثيم }} \\
\hline & $\mathrm{M} \pm \mathrm{SD}$ & & & & $\mathrm{M} \pm \mathrm{SD}$ & & $\mathrm{M} \pm \mathrm{SD}$ & & \\
\hline \multicolumn{4}{|c|}{$2.05 \pm 0.8$} & \multicolumn{2}{|r|}{$113.5 \pm 8.5$} & & $97 \pm 8.8$ & \multicolumn{2}{|c|}{ (ع.ذهبية+بعق آجلكتية } \\
\hline \multicolumn{4}{|c|}{$2.25 \pm 0.9$} & \multicolumn{2}{|r|}{$115.5 \pm 12$} & & $97.7 \pm 10$ & \multicolumn{2}{|c|}{ سلبية الغرام إثريكية } \\
\hline
\end{tabular}

جدول رقم 9: يظهر منوسط عدد الأيام حتى التلقيح الاصطناعي الأول لمجموعات أبقار الدراسة

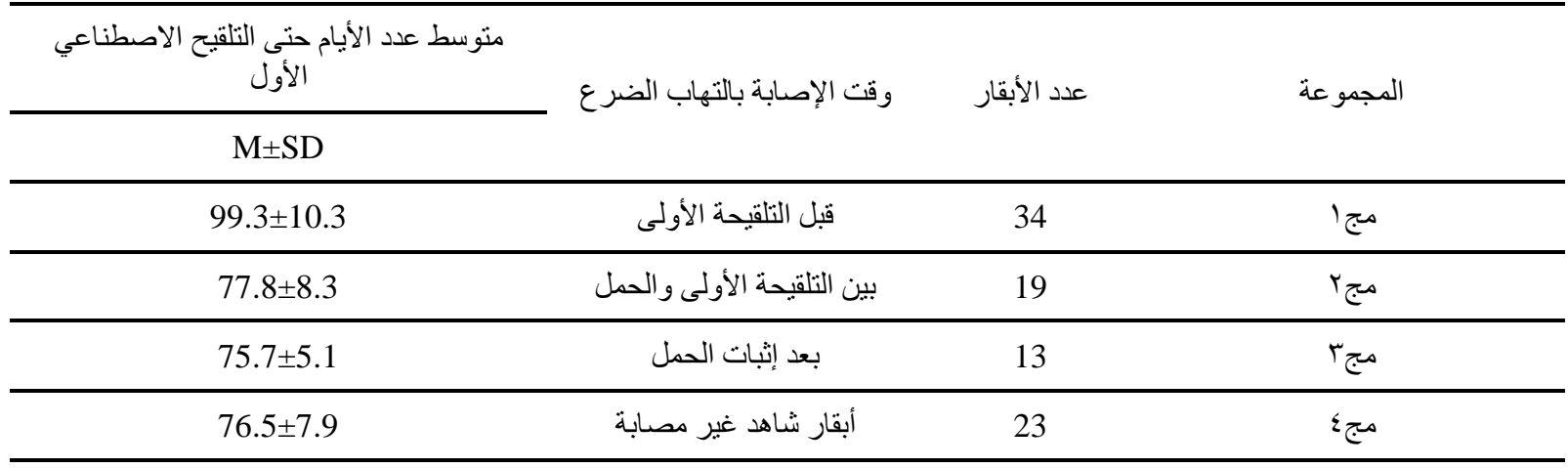


Assiut Vet. Med. J. Vol. 61 No. 144 January 2015

جدول • 1 : يظهر متوسط عدد التلقيحات الاصطناعية اللازمة للعُشر لمجموعات أبقار الدراسة.

\begin{tabular}{|c|c|c|c|}
\hline متوسط عدد التلقيحات الاصطناعية اللازمة & وقت الإصابة بالتهاب الضرع & عدد الأبقار & المجمو عة \\
\hline $\mathrm{M} \pm \mathrm{SD}$ & & & \\
\hline $2.3 \pm 1.01$ & قبل التلقيحة الأولى & 34 & مجا \\
\hline $3.68 \pm 0.8$ & بين التلقيحة الأولى و الحمل & 19 & مجن \\
\hline $2.07 \pm 0.2$ & بعد إثبات الحمل & 13 & مجr \\
\hline $2.04 \pm 0.8$ & أبقار شاهد غير مصابة & 23 & مج؟ \\
\hline
\end{tabular}

جدول 11 1 يظهر منوسط الفترة المفتوحة لمجموعات أبقار الدراسة.

\begin{tabular}{|c|c|c|c|}
\hline متوسط الفترة المفتوحة & \multirow{2}{*}{ وقت الإصابة بالتهاب الضرع } & \multirow{2}{*}{ عدد الأبقار } & \multirow{2}{*}{ ل لمجموعة } \\
\hline $\mathrm{M} \pm \mathrm{SD}$ & & & \\
\hline $118.1 \pm 14.3$ & قبل التلقيحة الأولى & 34 & مجا \\
\hline $151.7 \pm 27.7$ & بين التلقيحة الأولى و الحمل & 19 & مجr \\
\hline $98.5 \pm 5.72$ & بعد إثبات الحمل & 13 & مجr \\
\hline $95.6 \pm 12.1$ & أبقار شاهد غير مصابة & 23 & 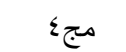 \\
\hline
\end{tabular}

\section{DISCUSSION}

المناقشنة

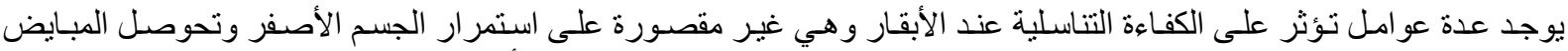

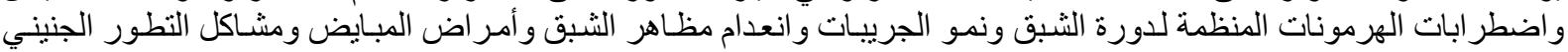

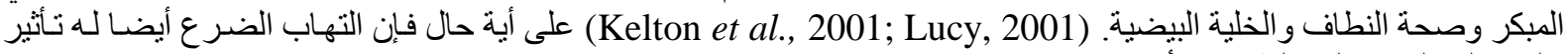
Barker et al., 1998; Huszenicza et al., 1998; Oliver et al., 2000; Schrick ) سلبي على الكفاءة التناسلية عند الأبقان

.(et al., 2001; Santos et al., 2004; Huszenicza et al., 2005

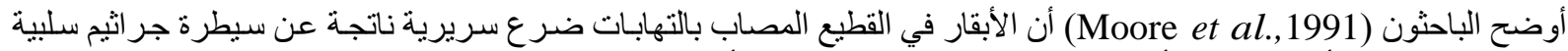

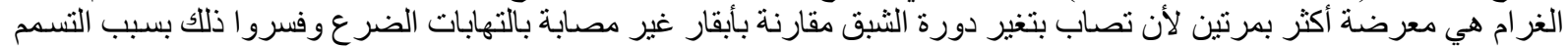

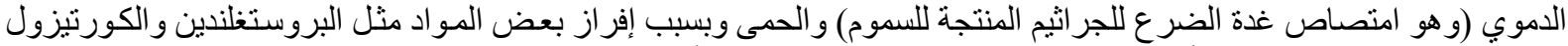

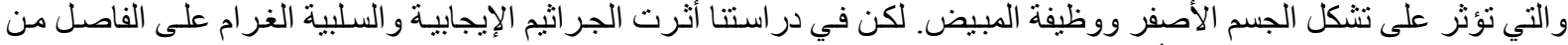
الو لادة حتى التلقيح الاصنطناعي الأول.

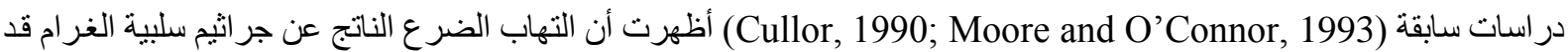

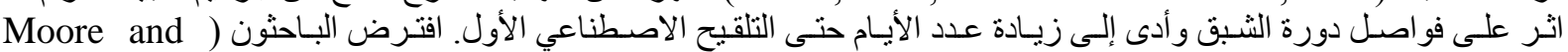

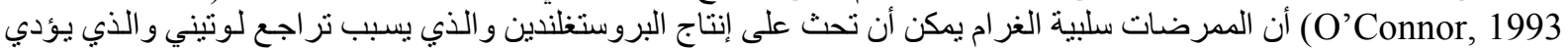

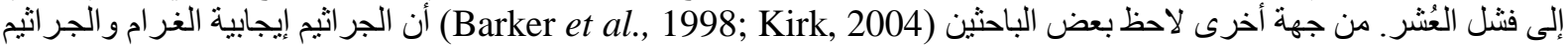

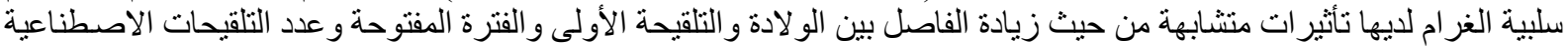

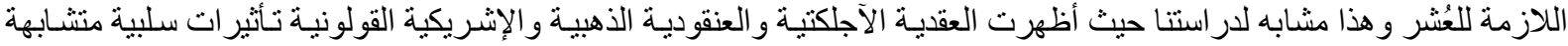

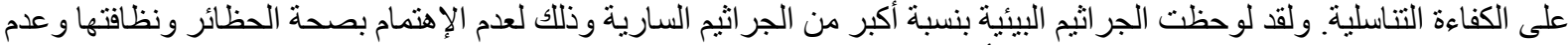

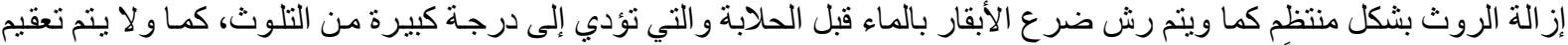

فناجين آلة الحلابة مطلقاً.

على أية حال حسب الباحثين (Salyers and Whitt, 1994) فإن جدار الخلية الجرثومية للجر اثثيم الإيجابية و السلبية الغرام

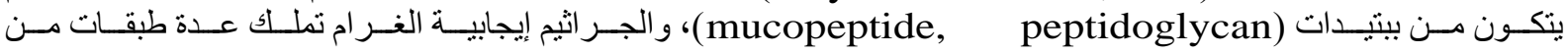




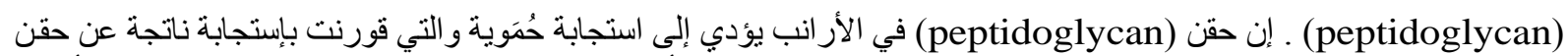

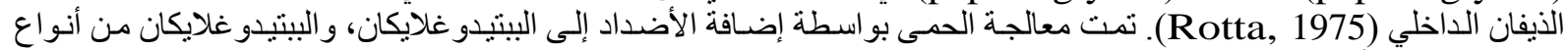

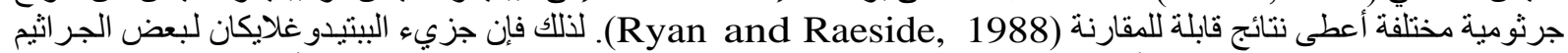

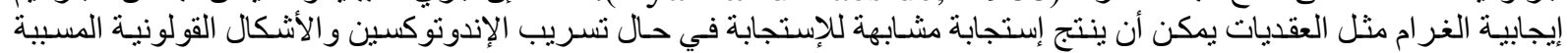

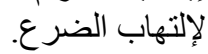

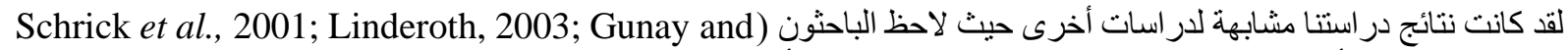

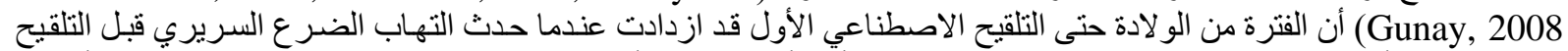

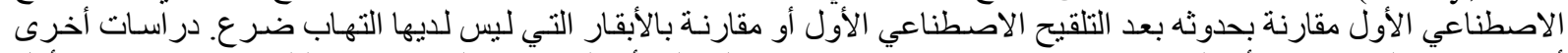

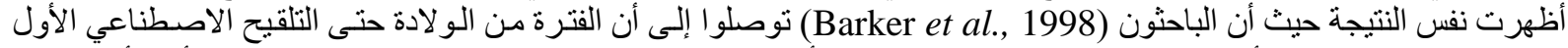

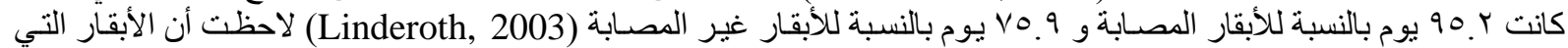

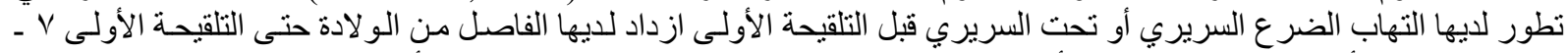

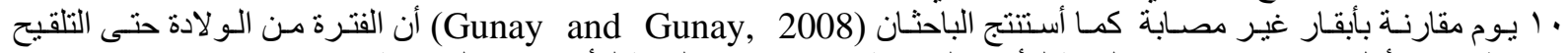

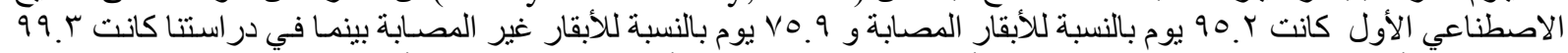

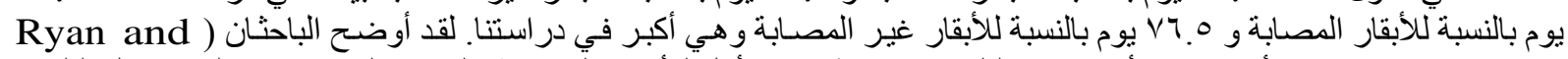

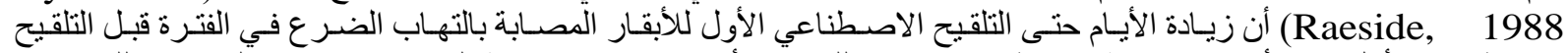

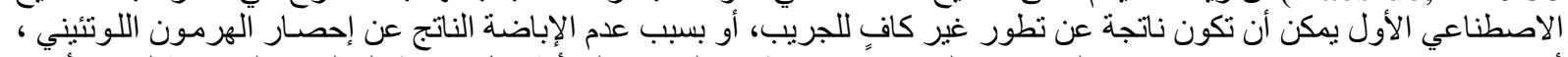

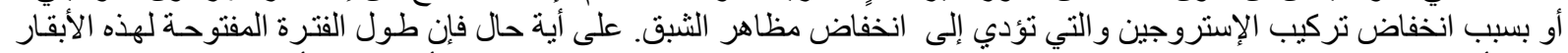

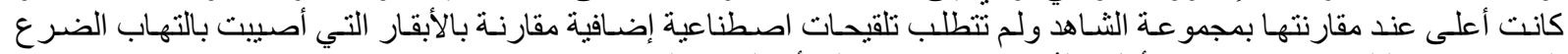
السريري بين التلقيح الاصطناعي الأول و العُشر ، و وذا يثنير إلى أن الكيسة البيضية كانت حية.

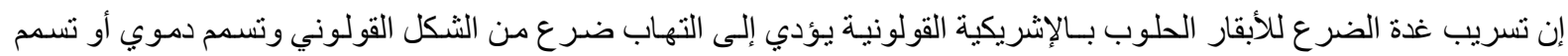

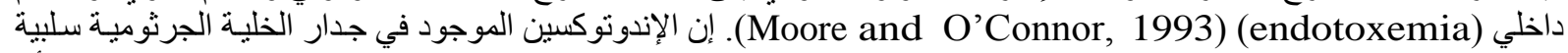

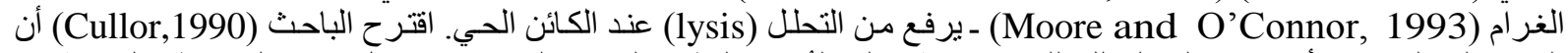

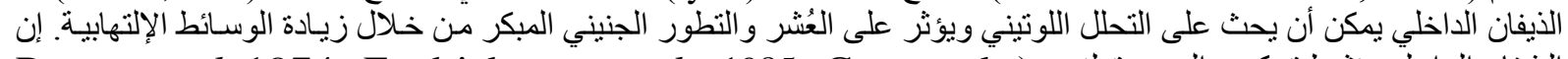

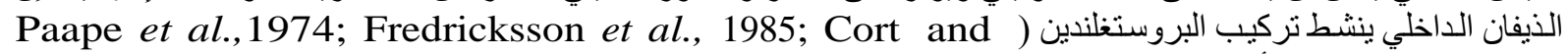
Lopez-Diaz and Bosu, 1992; Battaglia et al., ) (glucocorticoids)(أيضا ينشط) (Kindahl, 1990.

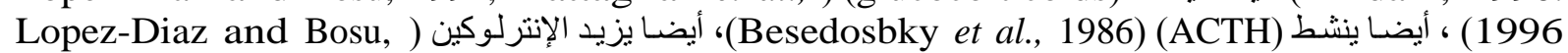
1992)، يخفض من (Battaglia et al.,1996) (GnRH release)، تسريب الإندونو كسين يؤدي إلى استجابة بيريتك (Dyretic)

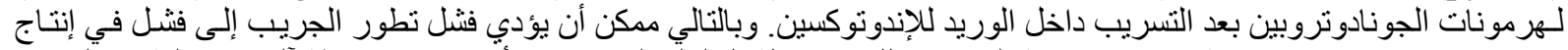

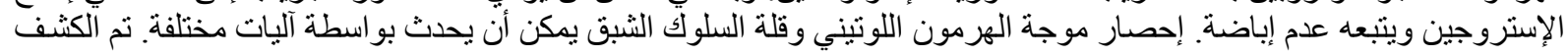

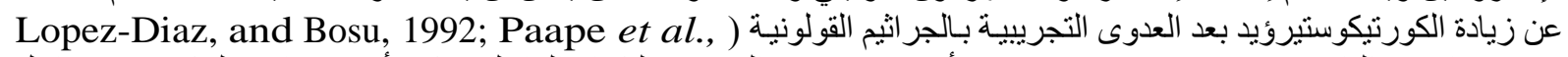

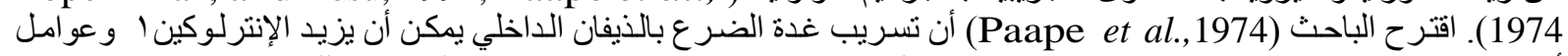

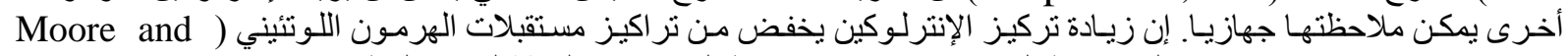

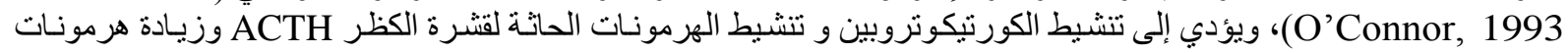

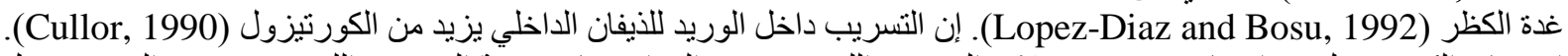

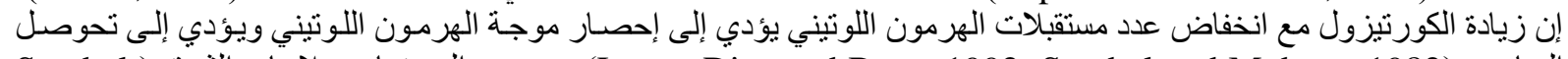

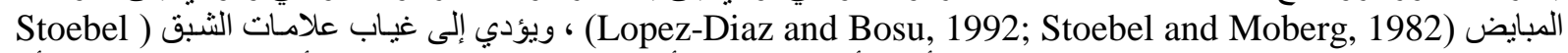

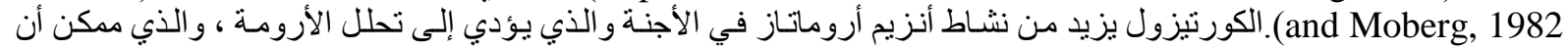
يؤدي إلى إحصار موجة الهرمون اللوتيني بو اسطة تثبيط تثكل الإستروجين من المبيض (Peter et al., 1990).

وجد الباحث (Kirk, 2004) أن الأبقار التي أصيبت بالتهاب الضرع قبل التلقيح الاصطناعي الأول حدث لديها زيادة في عدد الأيسام حتى التلقيحة الأولى.

زيادة الفترة المفتوحة عند الأبقار المصابة بالتهاب الضر ع بين التلقيح الاصطناعي الأول و العُشر في دراستنا تو افق مع دراسات عدة

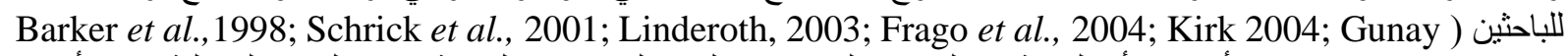
(and Gunay, 2008 كما أوضحو أن الوقاية من التهابات الضرع في الفترة المبكرة من الحلابة يحسن الكفاءة التناسلية عند الأبقار.

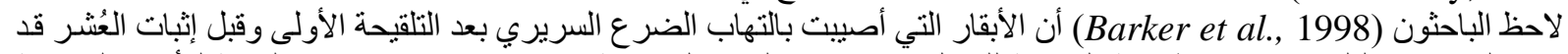

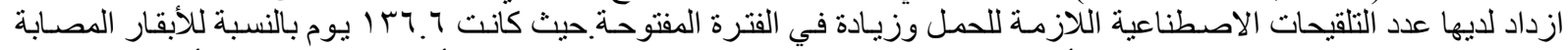

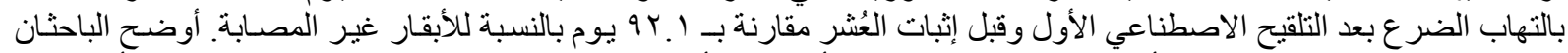
(Gunay and Gunay, 2008)

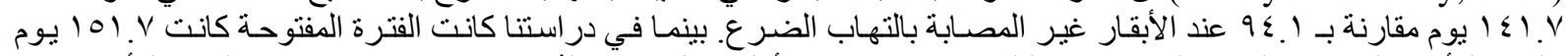
بالنسبة للأبقار المصابة بالتهاب الضر ع بعد التلقيح الاصطناعي الأول وقبل إثبات العُشر مقارنة بـ 7. 
المصابة وهي أكثر ها.. دراسات سابقة (Barker et al., 1998; Linderoth, 2003) أظهرت أن التهابات الضر ع ؤن أدت إلى تأخير

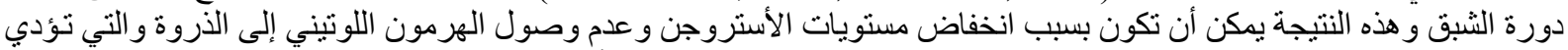

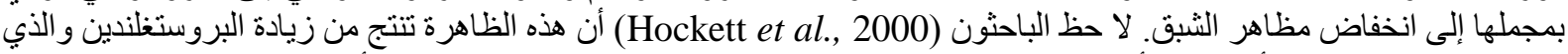

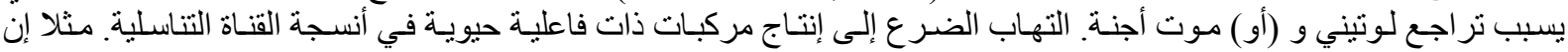

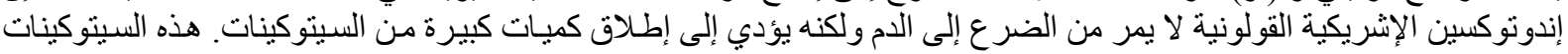

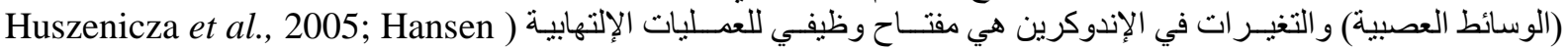

.(et al., 2004

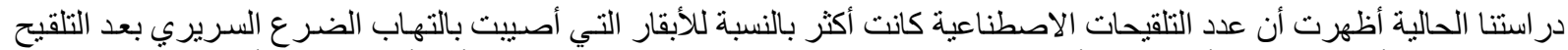

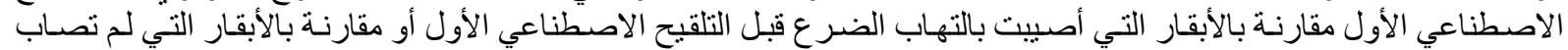

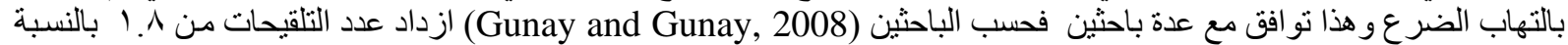

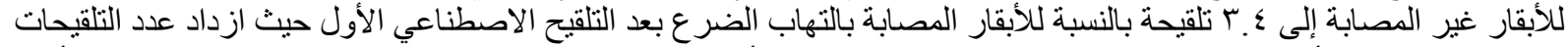

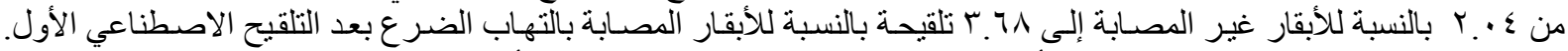

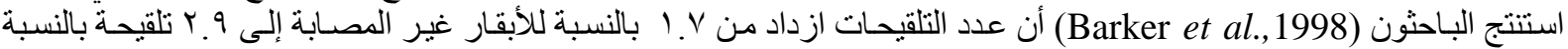

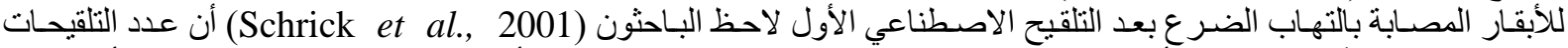

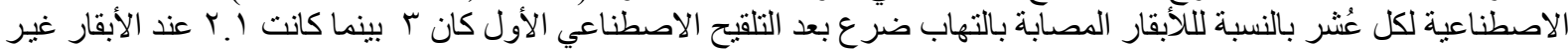
المصابة.

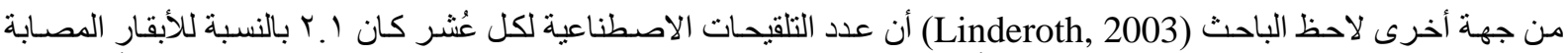

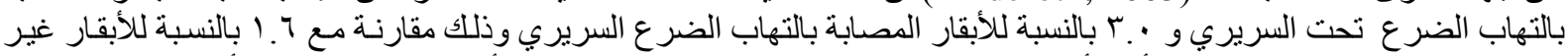

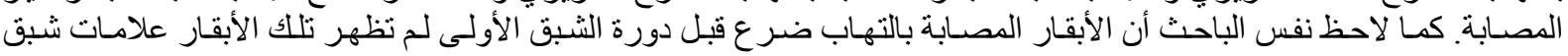

واضحة.

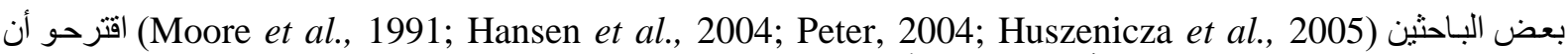

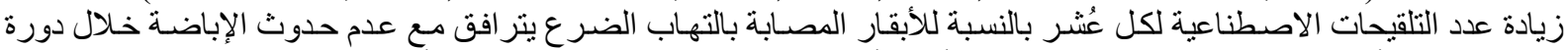

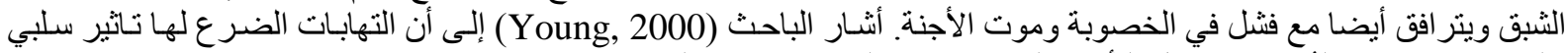

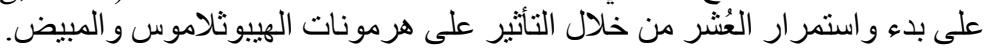

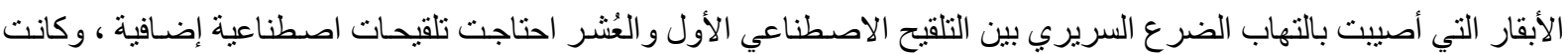

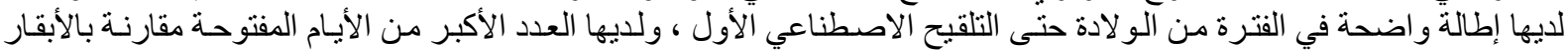

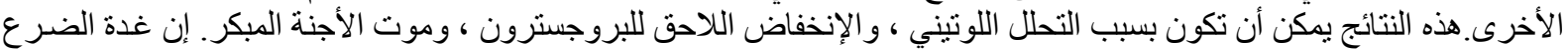

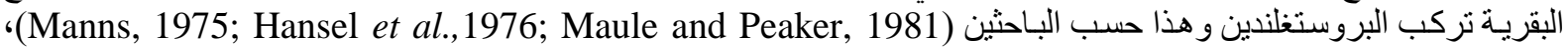

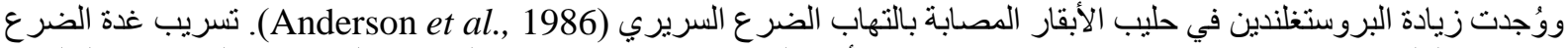

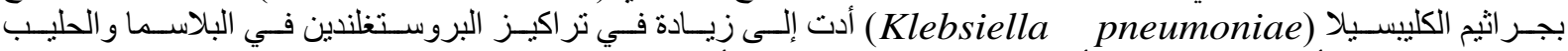

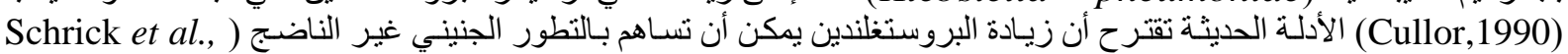

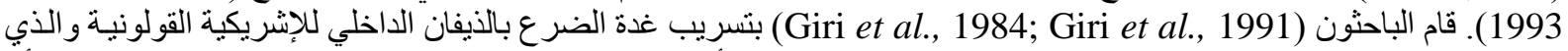

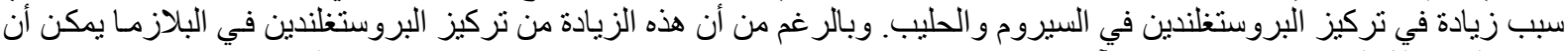

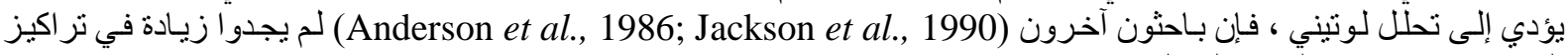
الهرمون بعد تسريب الذيفان الداخلي.

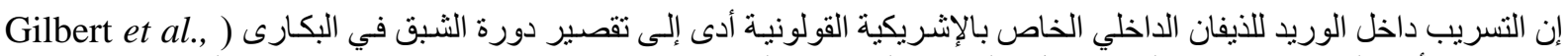

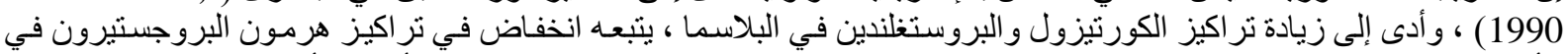

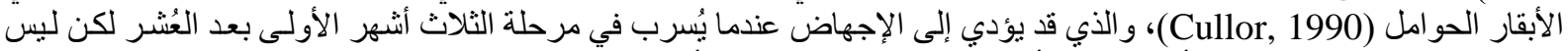

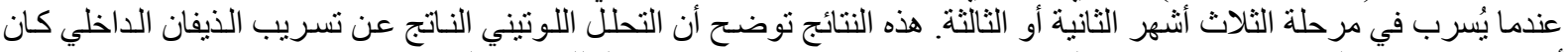

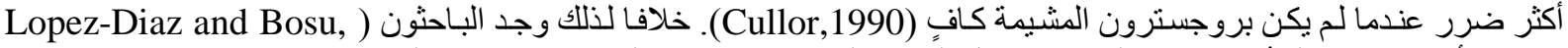

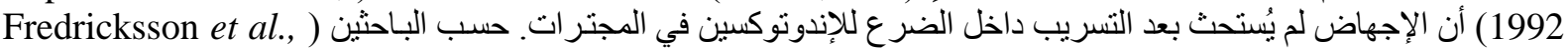

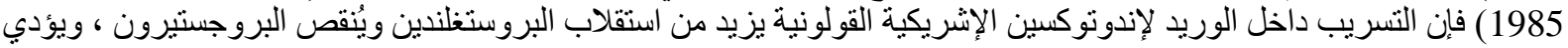

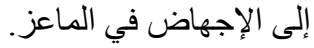

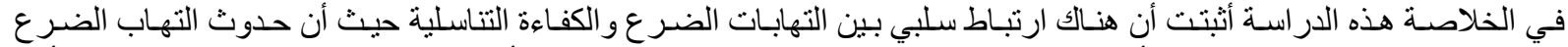

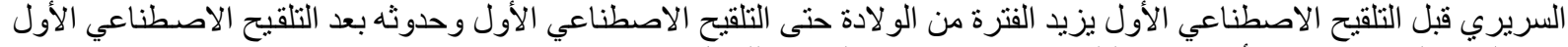

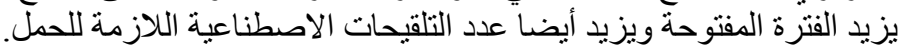




\section{CONCLUSIONS}

الاستتناجات

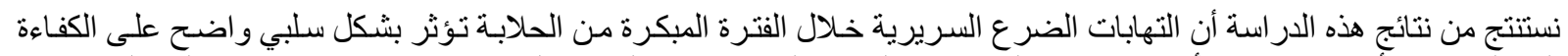

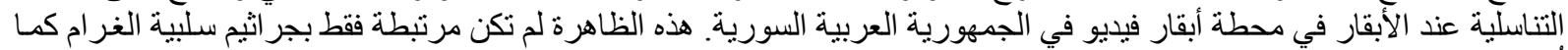

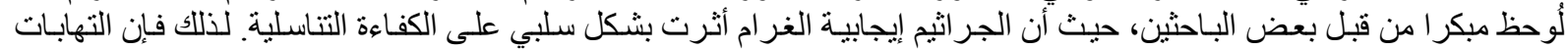

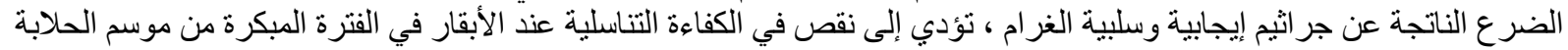

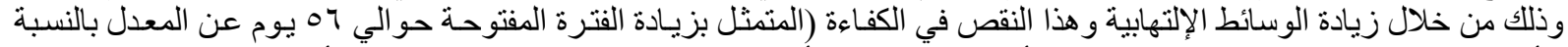

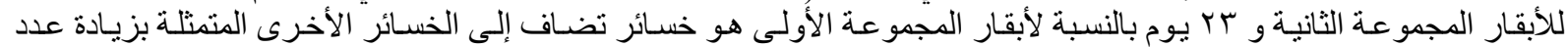

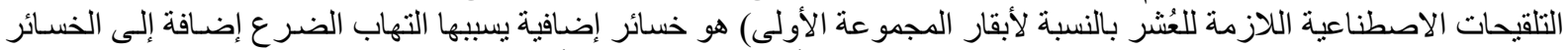

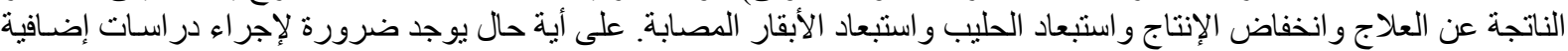
حول نأثير التهابات الضرع على الكفاءة التناسلية متضمنة علاقة التهاب الضر عاد بالإجهاض وتقدير الخسائر الناجمة عنها بشكل شامل.

\section{REFERENCES \\ المراجـع}

Ahmadzadeh, A.; A. Mark. McGuire and Joseph C. Dalton (2010): Interaction between Clinical Mastitis, Other Diseases and Reproductive Performance in Dairy Cows WCDS Advances in Dairy Technology (2010) Volume 22: 83-95.

Anderson, L.K.; Kindahl, H.; Smith, R.A.; Davis, L.E. and Gustafsson, B.K. (1986): Endotoxininduced bovine mastitis: arachidonic acid metabolites in milk and plasma and effect of flunixin meglumine. Am. J. Vet. Res. 47: 1373-1377.

Barker, A.R.; Schrick, F.N.; Lewis, M.J.; Dowlen, H.H.and Oliver, S.P. (1998): Influence of clinical mastitis during early lactation on reproductive performance of Jersey cows. J Dairy Sci 81: 1285-1290.

Battaglia, D.F.; Bowen, J.M.; Krasa,H.B.; Thrun, L.A.; Viguie, C. and Karsch, F.J. (1996): Immune stress and reproductive neuroendocrine function: physiologic evidence for profound inhibition of GnRH secretion. Biol. Reprod. 54 (Suppl. 1): 93.(Abstr.).

Besedosbky, H.; DelRey, A.; Sorkin, E. and Dinarello, C.A. (1986): Immunoregulatory feedback between interleukin-1 and glucocorticoid hormones. Science (Washington, D C) 233: 652-654.

Blowey, R.W. and Edmondson, P. (1995): Mastitis Control in Dairy Herds: An Illustrated and Practical Guide. Farming Press Books, UK.

Cort, N. and Kindahl. H. (1990): Endotoxin-induced abortion in early pregnant gilts and its prevention by flunixin meglumine. Acta Vet. Scand. 31: 347-358.

Cullor, J.S. (1990): Mastitis and its influence upon reproductive performance in dairy cattle. Pages 176-180 in Proc. Int. Symp. Bovine Mastitis, Indianapolis, IN. Natl. Mastitis Counc., Inc. and Am. Assoc. Bovine Pract., Arlington, VA.

Eberhart, R.J.; Harmon, R.J.; Jasper, D.E.; Natzke, R.P.; Nickerson, S.C.; Reneau, J.K.; Row, E.H.; Smith, K.L. and Spencer, S.B. (1987): Current Concepts of Bovine Mastitis. 3rd ed. Natl. Mastitis Council, Inc., Arlington, VA.

Fleischer, P.; Metzner, M.; Beyerbach, M.; Hoedemaker, M. and Klee, W. (2001): The relationship between milk yield and the incidence of some diseases in dairy cows. J. Dairy Sci. 84: 2025-2035.

Frago, F.; Ahmadzadeh, A.; Shafii, B.; Dalton, J.C.; Mcguire, M.A. and Price. W.J. (2004): Effect of clinical mastitis and other diseases on reproductive performance of Holstein cows. J. Dairy Sci. 87 (Suppl): 258

Fredricksson, G.; Kindahl, J. and Edquist, L.E. (1985): Endotoxin-induced prostaglandin release and corpus luteum function in goats. Anim. Reprod. Sci. 8: 109-121.

Gilbert, R.O.; Bosu, W.T.K. and Peter. A.T. (1990): The effect of Escherichia coli endotoxin on luteal function in Holstein heif ers. Theriogenology 33: 645-651.

Giri, S.N.; Stabenfeldt, G.H.; Mosley, T.A.; Graham, T.W.; Bruss, M.L.; Bon Durant, R.H.; Cullor, J.S. and Osburn, B.I. (1991): Role of eicosanoids in abortion and its prevention by treatment with flunixin meglumine in cows during the first trimester of pregnancy. $\mathbf{J}$. Vet. Med. Ser. A 38: 445-459.

Giri, S.N.; Chen, Z.; Carroll, E.J.; Mueller, R.; Schiedt, M.J. and Panico, L. (1984): Role of prostaglandins in pathogenesis of bovine mastitis induced by Escherichia coli endotoxin. Am. J. Vet. Res. 45: 586-591.

Gunay, A. and Gunay, U. (2008): Effects of Clinical Mastitis on Reproductive Performance in Holstein Cows. ACTA VET. BRNO 2008, 77: 555-560; doi: 10.2754/avb200877040555. 
Hansel, W.; Hixon, J.; Shemesh, M. and Tobey, D. (1976): Concen- trations and activities of prostaglandins of the F series in bovine tissue, blood, and milk. J. Dairy Sci. 59: 1353-1365.

Hansen, P.J.; Soto, P. and Natzke, R.P. (2004): Mastitis and fertility in cattle - possible involvement of inflammation or immune activation in embryonic mortality. Am. J. Reprod Immunol 51: 294-301.

Harmon, R.H. (1994): Mastitis and genetic evaluation for somatic cell count-physiology of mastitis and factors affecting somatic cell counts. J. Dairy Sci, 77: 2103-2012.

Hockett, M.E.; Hopkins, F.M.; Lewis, M.J.; Saxton, A.M.; Dowlen, H.H.; Oliver, S.P. and Schrick, F.N. (2000): Endocrine profiles of dairy cows following experimentally induced clinical mastitis during early lactation. Anim Reprod Sci 58: 241-251.

Huszenicza, G.; Janosi, S.; Kulcsar, M.; Korodi, P.; Dieleman, S.J.; Bartyik, J.; Rudas, P. and Ribiczeiszabo, P. (1998): Gram-negative mastitis in early lactation may interfere with ovarian and certain endocrine functions and metabolism in dairy cows. Reprod Domest Anim 33: 147-153.

Huszenicza, G.Y.; S.Z. Janosi, M. Kuksar, P. Korodi, J. Reiczigel, L. Katai, A.R. D.E. Peters, and Rensis, F. (2005): Effects of clinical mastitis on ovarian function in post-partum dairy cows. Reprod Domest Anim 40: 199-204.

Jackson, J.A.; Shuster, D.E.; Silvia, W.J. and Harmon, R.J. (1990): Physiological responses to intramammary or intravenous treatment with endotoxin in lactating cows. J. Dairy Sci. 73: 627-632.

Julie-Pallant (2005): SPSS Survival Manual. A step by step guide to data analysis using SPSS for Windows (Version 12) National Library of Australia: p 214.

Kelton, D.; Petersson, C. and Hansen, D. (2001): Associations between clinical mastitis and pregnancy on Ontario dairy farms. Proceedings of the 2nd International Symposium on Mastitis and Milk Quality. Canada, pp. 200-202.

Kirk, J.H. (2004): Effect of clinical mastitis on production and reproduction (E suppl): E1-E2 (http://www.vetmed. ucdavis.edu/vetext/INF-DA/Mastitis-on-Produc.pdf), accessed December 7, 2006.

Linderoth, S. (2003): Don't let subclinical mastitis zap reproductive efficiency. Dairy herd management (http://www.dairyherd. com/print Friendly. asp?ed_id=2332), accessed December 15, 2006.

Lopez-Diaz, M.C. and Bosu, W.T.K. (1992): A review and update of cystic ovarian degeneration in ruminants. Theriogenology 37: 1163-1183.

Lucy, M.C. (2001): ADSA foundation scholar award - reproductive loss in high-producing dairy cattle: Where will it end? J. Dairy Sci. 84: 1277-1293.

Manns, J.G. (1975): The excretion of prostaglandin F2a in milk of cow. Prostaglandins 9: $463-474$.

Maule, F.M. and Peaker, M. (1981): Prostaglandins and lactation. Acta Vet. Scand. Suppl. 77 : 229-310.

Moore, D.A. and O'Connor, M.L. (1993): Coliform mastitis: its possible effects on reproduction in dairy cattle. Pages 162-166 in Proc. Natl. Mastitis Counc., Kansas City, MO. Natl. Mastitis Counc., Inc., Arlington, VA.

Moore, D.A.; Cullor, J.S.; BonDurant, R.H. and Sischo, W.M. (1991): Preliminary field evidence for the association of clinical mastitis with altered interestrus intervals in dairy cattle. Theriogenology 36: 257-265.

Oliver, S.P.; Schrick, F.N.; Hockett, M.E. and Dowlen, H.H. (2000): Clinical and subclinical mastitis during early lactation impairs reproductive performance of dairy cows. Proceedings of National Mastitis Council, Inc. Regional Meeting (Cleveland, Ohio, 24 August, 2000), pp. 34-51.

Paape, M.J.; Schultze, W.D.; Desjardins, C. and Miller, R.H. (1974): Plasma corticosteroid circulating leukocyte and milk somatic cell responses to adrenocorticosteroid, circulating leukocyte and milk somatic cell response to Escherichia coli endo toxininduced mastitis. Proc. Soc. Exp. Biol. Med. 145: 553-559.

Peter, A.T.; Simon, J.E.; Luker, C.W. and Bosu, W.T.K. (1990): Site of action for endotoxininduced cortisol release in the suppression of preovulatory luteinizing hormone surges. Therioge nology 33: 637-643.

Peter, A.T. (2004): An update on cystic ovarian degeneration in cattle. Reprod Domest Anim 39: 1-7.

Quinn, P.J.; Carter, M.E.; Markey, B.K. and Carter, G.R. (1999): Clinical Veterinary Microbiology. Harcourt Publishers Ltd: London. 322-324.

Radostitis, O.M.; Blood, D.C. and Gay, C.C. (1994): Veterinary Medicine: A Text Book of the diseases of Cattle, Sheep, Pigs, Goats and Hosers. $8^{\text {th }}$ Edition. Bailliere - Tindall, London, UK.

Rotta, J. (1975): Endotoxin-like properties of the peptidoglycan. Z. Immunitaetsforsch. 149: 230-244.

Ryan, P.L. and Raeside, J.I. (1988): Steroidogenesis in granulosa cells after induction of large cystic follicles with adrenocorticotropin (ACTH) in the cyclic gilt. Page 458 in Proc. 11th Int. Congr. Anim. Reprod. AI, Dublin, Ireland. 
Salyers, A.A. and Whitt, D.D. (1994): Bacterial Pathogenesis- A Molecular Approach. ASM Press, Washington, DC.

Santos, J.E.P.; Cerri, R.L.A.; Ballou, M.A.; Higginbotham, G.E. and Kirk, J.H. (2004): Effect of timing of first clinical mastitis occurrence on lactational and reproductive performance of Holstein dairy cows. Anim Reprod Sci 80: 31-45 559.

Schrick, F.N.; Hockett, M.E.; Saxton, A.M.; Lewis, M.J.; Dowlen, H.H. and Oliver, S.P. (2001): Influence of subclinical mastitis during early lactation on reproductive parameters. J Dairy Sci 84: 1407-1412.

Schrick, F.N.; Inskeep, E.K. and Butcher, R.L. (1993): Pregnancy rates for embryos transferred from early postpartum beef cows into recipients with normal estrous cycles. Biol. Reprod. 49: 617-621.

Smith K.L.; Todhunter, D.A. and Schoenberger, P.S. (1985): Environmental Mastitis: Cause, Prevalence, Prevention 1,2. J. Dairy Sci. 68: 1531-1553.

Stoebel, D.P. and Moberg, G.P. (1982): Effect of adrenocorticotropin and cortisol on luteinizing hormone surges and estrus behavior of cows. J. Dairy Sci. 65: 1016-1024.

Young, A. (2000): Can mastitis have an effect on reproduction? Dairy management. November http://extension. usu.edu/files/agpubs/mastrepr. htm, accessed December 7, 2006. 